\title{
Novel Mutations in the TAZ Gene in Patients with Barth Syndrome
}

\author{
Mazurová S. ${ }^{1}$, Tesařová M. ${ }^{1}$, Magner M. ${ }^{1}$, Houšt'ková H. ${ }^{2}$, Hansíková H. ${ }^{1}$, \\ Augustínová J. ${ }^{1}$, Tomek V. ${ }^{3}$, Vondráčková A. ${ }^{1}$, Zeman J.. ${ }^{1}$ Honzík T. ${ }^{1}$ \\ ${ }^{1}$ Department of Pediatrics and Adolescent Medicine, First Faculty of Medicine, \\ Charles University in Prague and General University Hospital in Prague, Prague, \\ Czech Republic; \\ 2Department of Pediatrics, First Faculty of Medicine, Charles University in Prague \\ and Thomayer Hospital, Prague, Czech Republic; \\ ${ }^{3}$ Children's Heart Center, University Hospital Motol, Prague, Czech Republic \\ Received February 4, 2013; Accepted August 14, 2013.
}

Key words: Barth syndrome - Cardiomyopathy - Growth failure - Neutropenia 3-methylglutaconic aciduria

\begin{abstract}
Barth syndrome is an X-linked recessive disorder that is caused by mutations in Taffazin gene (TAZ), leading to severe cardiolipin deficiency which results in respiratory chain dysfunction. Barth syndrome is characterized by cardiomyopathy, neutropenia, skeletal myopathy, growth deficiency and 3-methylglutaconic aciduria. In this paper, we present clinical, biochemical and molecular data of the first four Czech patients from four unrelated families diagnosed with this rare disease. The mean age of onset was $5.5 \pm 3.8$ months. One child suffered from sudden cardiac death at the age of 2 years, the age of living patients is between 3 and 13 years. Muscle hypotonia was present in all four patients; cardiomyopathy and growth retardation in three and neutropenia in two of them. Two patients manifested a dilated and one patient a hypertrophic cardiomyopathy. A characteristic laboratory abnormality was the intermittently increased excretion of 3-methylglutaconic acid. Three novel hemizygous mutations in the TAZ gene were found (c.584G>T; c.109+6T>C; c.86G>A). We conclude that Barth syndrome should be included in differential diagnosis of cardiomyopathy in childhood, especially in the cooccurrence of dilated cardiomyopathy and 3-methylglutaconic aciduria.
\end{abstract}

Institutional support was provided by research programs PRVOUK-P24/LF1/3 (HH), by the Research Project RVO-VFN64165/2012 (JZ) and by the project for conceptual development of research organization 00064203 from Ministry of Health, Czech Republic (VT) and by the grants IGA NT13114/4 (MT, AV) and IGA NT14156/3 (TH, SM, MM).

Mailing Address: Assoc. Prof. Tomáš Honzík, MD., PhD., Department of Pediatrics and Adolescent Medicine, First Faculty of Medicine, Charles University in Prague and General University Hospital in Prague, Ke Karlovu 2, 12808 Prague 2, Czech Republic; Phone: +420 224967 792; Fax: +420 224967 713; e-mail: tomas.honzik@vfn.cz 


\section{Introduction}

Barth syndrome (BTHS) is an X-linked recessive disorder that is caused by mutations in the Taffazin gene (TAZ) at Xq28 (Bolhuis et al., 1991; Bione et al., 1996). BTHS was first described by Barth et al. in 1983 in an extended pedigree with dilated cardiomyopathy (CMP), skeletal myopathy and neutropenia. BTHS is also characterized by growth failure and 3-methylglutaconic aciduria (3-MGA); note that 3-MGA is not specific to BTHS and is classified as 3-MGA type II (Kelley et al., 1991; Christodoulou et al., 1994). In addition, other features such as decreased plasma cholesterol level, lactic acidosis, hyperammonemia and cognitive difficulties have been reported (Donati et al., 2006; Mazzocco et al., 2007; Yen et al., 2008). The disease course can be variable, even within families (Johnston et al., 1997; Barth et al., 2004; Hauff and Hatch, 2006). The estimated incidence of BTHS (according to www.barthsyndrome.org register) is 1 to $300,000-400,000$ male births, but accurate incidence is not known and BTHS seems to be underdiagnosed.

Taffazin gene encodes a protein involved in transacylation of cardiolipin, an essential mitochondrial phospholipid. The protein defect causes an important reduction in incorporation of linoleic acid into the side chain of cardiolipin. Moreover, there is a decreased pool size of cardiolipin which indicates accelerated cardiolipin degradation (Neuwald, 1997; Vreken et al., 2000; Hauff and Hatch, 2006). Cardiolipin constitutes a component of the inner mitochondrial membrane, provides stability to the mitochondrial respiratory chain and its loss results in respiratory chain dysfunction (Neuwald, 1997; Barth et al., 2004; Brandner et al., 2005). Mutations in TAZ gene are associated with BTHS, but contribute also to the left ventricular noncompaction (LVNC) and a CMP characterized by loose, trabeculated myocardium (D’Adamo et al., 1997; Brady et al., 2006; Ronvelia et al., 2012).

In this paper, we present clinical, biochemical and molecular characteristics of four Czech patients from four unrelated families diagnosed with BTHS. We focused specifically on the three novel mutations found in the TAZ gene and cardiological findings in these patients with the aim of bringing proper attention to BTHS in differential diagnosis of dilated/hypertrophic CMP in children.

\section{Material and Methods}

Patient reports

Patient 1:

The boy was born at term as a first child of healthy non-consanguineous parents of Caucasian origin with birth weight of $2,595 \mathrm{~g}\left(<5^{\text {th }}\right.$ centile) and birth length of $48 \mathrm{~cm}$. The early postnatal adaptation was uneventful. Bilateral cryptorchidism was noted after birth. At the age of 4 months he was examined because of dyspnea during breast feeding, failure to thrive and short stature (weight of $4.1 \mathrm{~kg}$ and length of $58 \mathrm{~cm}$, both $<3^{\text {rd }}$ centile). The ECG showed sinus tachycardia with discordant T-waves and ST-segment depressions in the left precordium. Echocardiography revealed a diagnosis of dilated CMP with regional heterogeneity 
Figure 1A - Apical four-chamber view depicts a globular shape of severely dilated left ventricle (LV), whereas the size of right ventricle $(R V)$ is normal. Prominent trabeculations of the left ventricular wall is present, however without non-compaction of the left ventricle. Left atrium $(L A)$ is mildly dilated.
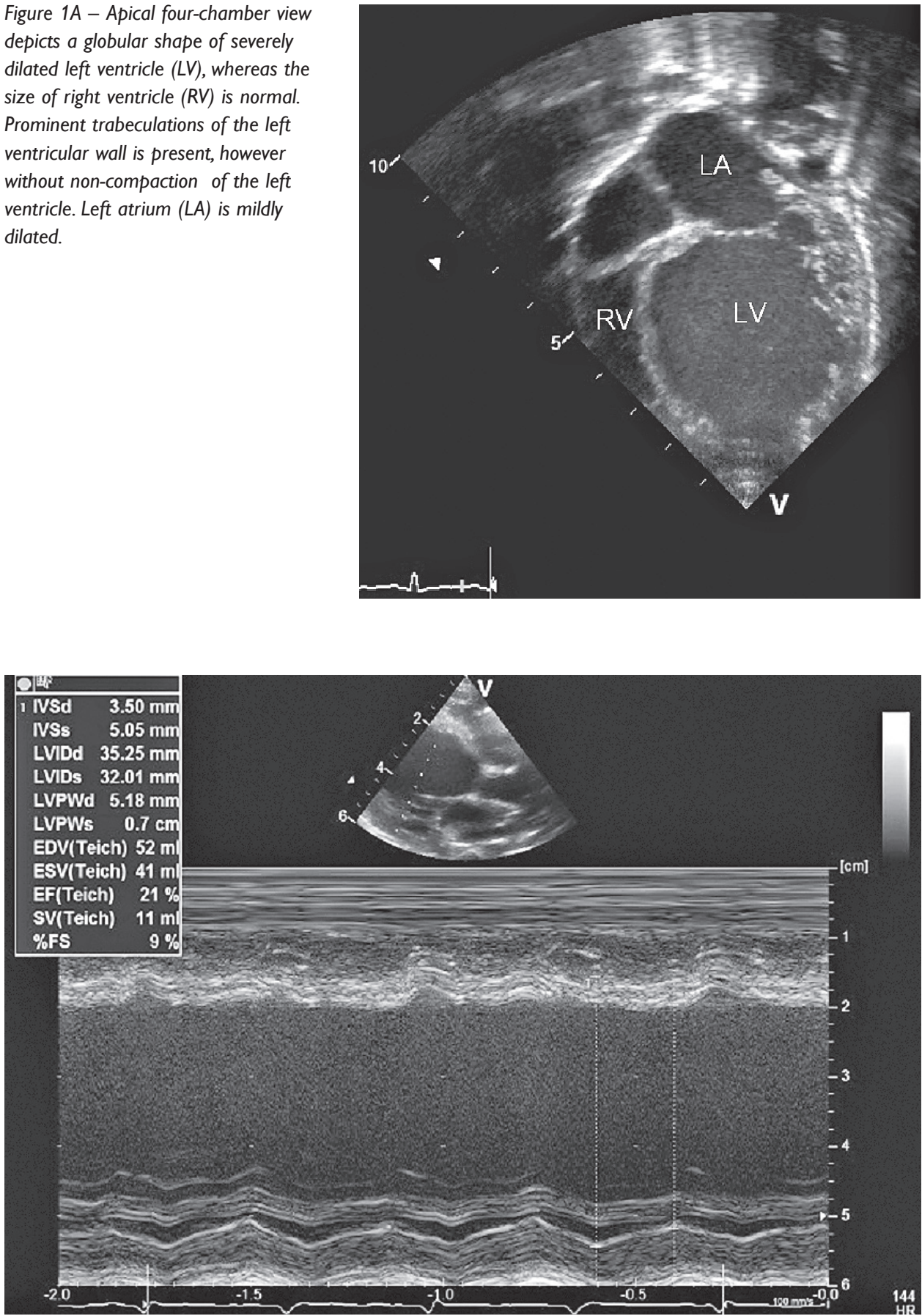

Figure $1 B-M$-mode in standard parasternal long axis view shows enlarged end-diastolic (LVIDd) and endsystolic (LVIDs) diameters and severely decreased parameters of left ventricular systolic performance (SF, EF).

Novel Mutations in the TAZ Gene in Patients with Barth Syndrome 


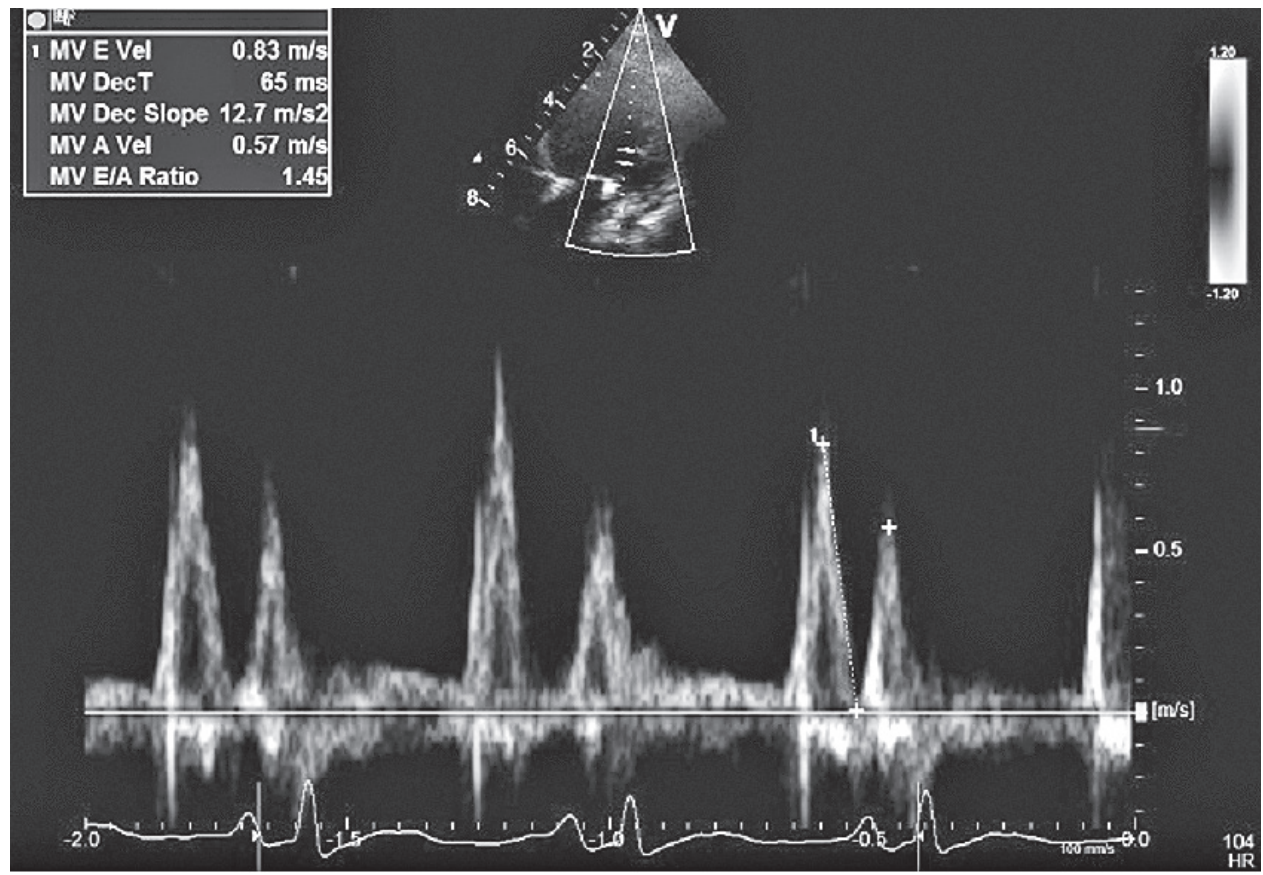

Figure $1 C$ - Pulsed Doppler examination from a four-chamber view proves a rapid deceleration time (MV Dec T) 65 ms as a sign of restrictive left ventricular filling pattern.

of left ventricular contraction. Left ventricle was dilated (left ventricle end-diastolic diameter (LVIDd) of $36 \mathrm{~mm}$; $176 \%$ of controls; $Z$ score +5.2 ) with severely decreased contractility and shortening fraction (SF) (6\%, normal range 30-42\%) and decreased ejection fraction (EF) of $12 \%$ (Figure $1 \mathrm{~A}-\mathrm{C}$ ). Restricted filling pattern of left ventricle (LV) was seen with short deceleration time 50-65 ms. Therapy of heart failure, consisting of digoxin, furosemide and ACE-inhibitors (angiotensin converting enzyme), brought no significant improvement. Metabolic investigation detected 3-MGAuria $60 \mathrm{mg} / \mathrm{g}$ creatinine (controls <15).

Skeletal myopathy with moderate gross motor development delay together with persistent growth failure and failure to thrive (length $70 \mathrm{~cm}$ and weight $7.89 \mathrm{~kg}$ ) was documented by physical examination at 21 months. Even though mild improvement in the severity of the LV dilatation (LVIDd Z score +3.5) and the contractility with SF of $15 \%$ and EF of $26 \%$ was found in control echocardiography, the boy suddenly died at the age of 2 years because of malignant arrhythmia (sudden cardiac arrest). At that time, hyperammonemia was not detected (ammonia concentration $52 \mu \mathrm{mol} / \mathrm{l}$, controls $<60$ ) but severe metabolic lactic acidosis (lactate $9.1 \mathrm{mmol} / \mathrm{l}$, controls <2.3; base deficit $13 \mathrm{mmol} / \mathrm{l}$, controls \pm 2.0 ), moderate hepatopathy (ALT $2.51 \mu \mathrm{kat} / \mathrm{l}$, AST $4.81 \mu \mathrm{kat} / \mathrm{l}$, controls $<0.63$; creatine kinase was within reference range) and poor glycemia level control 
(3.2-23.8 mmol/l) were observed. There was no history of neutropenia. Autopsy revealed endocardial fibroelastosis of the left ventricle with an extreme dilatation of both ventricles. Hepatosplenomegaly together with a severe liver steatosis were found as well.

\section{Patient 2:}

The firstborn male from a physiological gestation of healthy mother of Caucasian origin was born at 37 weeks of gestation vaginally, weighing 2,800 $\mathrm{g}$ and with a length of $49 \mathrm{~cm}$. The early postnatal adaptation was uneventful. The disease manifested at the age of 4 months with heart failure signs: poor feeding, dyspnea, apathy, poor peripheral perfusion, hepatomegaly and cyanosis.

On physical examination, loud systolic murmur in the whole precordium was found. Echocardiography revealed dilated CMP with EF $26 \%$ and moderate mitral regurgitation. The pharmacological therapy of heart failure was administered immediately, consisting of a combination of digoxin, carvedilol, ACE-inhibitors, spironolactone and furosemide. A remarkable improvement of the heart parameters and gradual normalization of EF $55-60 \%$ and LVIDd $112 \%$ were observed on therapy (at 2 years of age). Mild mitral regurgitation persisted. Electrocardiography (Holter monitoring) documented normal record.

Although there was a moderate muscle hypotonia and delayed postural development during the first year of life, at the age of 2 years nearly normal psychomotor development was observed. Social interaction and speech were not affected. Growth retardation was documented since 1 year of life. At three years of age, his height was $90.5 \mathrm{~cm}$ (5 $5^{\text {th }}$ centile) and weight $11.4 \mathrm{~kg}$ (weight for height $<3^{\text {rd }}$ centile). In addition, from birth gradual microcephalization occurred. The head circumference $(\mathrm{HC})$ declined from $13^{\text {th }}$ to the $1^{\text {st }}$ centile (at the age 3 years $\mathrm{HC}$ was $46 \mathrm{~cm}$ ), although his psychomotor development corresponds to his age.

A metabolic decompensation with hyperammonemia has not occurred, even in case of heart failure. The boy manifested neither neutropenia nor recurrent infections. Liver function tests were only mildly elevated (ALT $0.62 \mu \mathrm{kat} / \mathrm{l}$, AST $1.1 \mu \mathrm{kat} / \mathrm{l}$, controls $<0.63$; creatine kinase was within reference range). Levels of IGF-I and IGFBP-3 were decreased (23.8 $\mu \mathrm{g} / \mathrm{l}$, controls 49-171; $1.9 \mathrm{mg} / \mathrm{l}$, controls 2.83-5.18). Intermittent mild 3-MGAuria (range from normal to $23 \mathrm{mg} / \mathrm{g}$ creatinine, controls $<15$ ) and intermittent mild hyperlactacidemia (lactate $2.7 \mathrm{mmol} / \mathrm{l}$, controls $<2.3$ ) were found in metabolic investigation.

\section{Patient 3:}

This 13-year-old boy was born at term by uncomplicated vaginal delivery after an uneventful pregnancy; he is the second child of non-consanguineous parents of Caucasian origin. His birth weight was $3.1 \mathrm{~kg}$ and birth length was $50 \mathrm{~cm}$. He has two healthy sisters. The grandmother's brother (from maternal side) died at 
the age of 9 years due to not further specified heart disease and boy's mother's sister had a history of 3 miscarriages. Muscle hypotonia in our patient was noted shortly after birth, but without any feeding problems in this period. At the age of 3 months, he was examined because of poor feeding and hyposaturation during an acute respiratory tract infection. Hepatomegaly was observed on physical examination. Cardiological investigation revealed SF of 21\% (normal range of $30-42 \%$ ), decreased systolic function of LV accompanied by increased LVIDd of $200 \%$ of controls. The diagnosis of hypertrophic CMP without LV outflow tract obstruction was established. Cardiac function stabilized on therapy consisting of digoxin until the age of 2 years and ACE-inhibitors transiently; at present, no more than a regular use of beta-blocker is necessary. Echocardiography showed LV hypertrophy regression (LVIDd of 131\%) at the age of 13 years. Standard ECG demonstrated prolonged QTc of 488 milliseconds.

His psychomotor development was delayed at first. Muscle hypotonia is present until now; he is frequently more tired. However his mental skills were always age appropriate. He has a reduced high gaining, failure to thrive, but microcephaly did not emerge. At 13 years of age, his height was $148 \mathrm{~cm}$ (5. $7^{\text {th }}$ centile) and weight $29 \mathrm{~kg}$ (weight for height $<3^{\text {rd }}$ centile).

Neutropenia was detected at the age of 3 months and has been treated with filgrastim (granulocyte colony-stimulating factor - G-CSF) since 5 years of age. Neither hyperammonemia nor hepatopathy or elevated creatine kinase was documented. Mildly increased excretion of 3-MGA was found intermittently (range from normal to $50 \mathrm{mg} / \mathrm{g}$ creatinine, controls $<15$ ). Only once a borderline hypocholesterolemia (total blood cholesterol $2.54 \mathrm{mmol} / \mathrm{l}$, controls $>2.6 \mathrm{mmol} / \mathrm{l}$ ) was noted.

\section{Patient 4:}

The 9-year-old boy, from a third pregnancy of young, healthy, unrelated parents of Caucasian origin with insignificant family history, was born by a spontaneous vaginal delivery at 37 weeks of gestation with birth weight $3.2 \mathrm{~kg}$ and length $50 \mathrm{~cm}$. The early postnatal adaptation was uneventful. He was examined at the age of 12 months because of muscle hypotonia and gross motor development delay. The development of his motor skills improved in the toddler age, but muscle hypotrophy and hypotonia with an increased muscle fatigue persisted. His mental development has always been normal.

The patient repeatedly suffered from attacks of fever and aphthous stomatitis. At the age of 2.5 years neutropenia was found and the therapy with filgrastim (GM-CSF) was administered. After the beginning of therapy the hematologic parameters normalized as well as the clinical status of the patient. Even though he has a regular cardiological follow up by examination (ECG, echocardiography once a year), he never showed any cardiological abnormalities typically described in BTHS and never manifested heart failure. He presented reduced height gaining 
over time. At the age of 9 years he has a height of $130 \mathrm{~cm}$ (15 th centile) and a weight of $22.7 \mathrm{~kg}$ (5th centile).

Levels of IGF-I were decreased (25-36 $\mu \mathrm{g} / \mathrm{l}$, controls 49-171). Neither hyperammonemia nor hepatopathy or elevated creatine kinase was documented. Metabolic investigation revealed intermittently elevated urinary excretion of 3-MGA from normal to $50 \mathrm{mg} / \mathrm{g}$ creatinine (controls $<15$ ) together with intermittently increased excretion of fumarate (normal to $25 \mathrm{mg} / \mathrm{g}$ creatinine, controls <15).

\section{Methods}

Total genomic DNA was isolated from blood lymphocytes by phenolchloroform extraction. All 11 exons and adjacent intronic regions of the TAZ gene were amplified by PCR and analyzed by direct sequencing at genetic analyzer ABI3100 Avant (Applied Biosystems, USA). PCR primers are available upon request.

RNA was isolated from lymphocytes of patient 2 and patient 4 by TriReagent (MRC Inc., USA) according to manufacturer's instructions. Total mRNA was transcribed to cDNA with use of SuperScript III reverse transcriptase (LifeTechnologies, USA) and TAZ cDNA corresponding to reference sequence ENST00000299328 was amplified in 4 overlapping fragments and analyzed by direct sequencing.

\section{Ethics}

Informed consent was obtained from parents.

\section{Results}

Clinical and laboratory findings

From 2007 to 2012, four male patients from four unrelated families were diagnosed with BTHS. The mean age of disease onset was $5.5 \pm 3.8$ months. One child died suddenly due to malignant arrhythmia at the age of two years; the age range of the living patients is from 3 years to 13 years. Even though our patients manifested typical clinical features and laboratory abnormalities of BTHS, only muscle hypotonia (skeletal myopathy) was present in all cases. CMP and growth retardation were documented in three and neutropenia in two of the patients. Intermittently increased excretion of 3-MGA was a consistent laboratory abnormality. Mothers of the patients are healthy without any clinical symptoms. In Table 1, we summarize the clinical and laboratory data of our patients with BTHS and compare them with the two patients series (total number of patients in selected literature is 43).

\section{Mutation analysis}

In patient 1 , a hemizygous mutation $c .86 \mathrm{G}>\mathrm{A}$ was found. The mutations results in p.Gly29Asp aminoacid substitution. Gly ${ }^{29}$ in Tafazzin is highly conserved among 
Table 1 - Clinical and laboratory data in four Czech patients with Barth syndrome in comparison to previously described patients' series (D'Adamo et al., 1997; Spencer et al., 2006)

\begin{tabular}{|c|c|c|c|c|c|c|}
\hline & \multicolumn{4}{|c|}{ Czech patients (current report) } & \multirow{2}{*}{$\begin{array}{l}\text { D'Adamo et } \\
\text { al. }(1997) \\
\text { total }(n=12)\end{array}$} & \multirow{2}{*}{$\begin{array}{c}\text { Spencer } \\
\text { et al. } \\
(2006)\end{array}$} \\
\hline & patient 1 & patient 2 & patient 3 & patient 4 & & \\
\hline TAZ gene mutation & c. $86 \mathrm{G}>\mathrm{A}$ & c. $109+6 \mathrm{~T}>\mathrm{C}$ & c. $280 \mathrm{C}>\mathrm{T}$ & c. $584 \mathrm{G}>\mathrm{T}$ & $10 / 12^{\mathrm{a}}$ & $30 / 31^{\mathrm{a}}$ \\
\hline Sex & male & male & male & male & males & males \\
\hline \multicolumn{7}{|l|}{ Prenatal data } \\
\hline $\begin{array}{l}\text { prematurity } \\
\text { (<37 weeks) }\end{array}$ & - & $-^{\mathrm{b}}$ & - & $-^{\mathrm{b}}$ & n.a. & n.a. \\
\hline IUGR ( $<5^{\text {th }}$ centile) & + & - & - & - & n.a. & n.a. \\
\hline \multicolumn{7}{|l|}{ Postnatal data } \\
\hline age of onset (months) & 3 & 4 & 3 & 12 & n.a. & n.a. \\
\hline presenting symptom & $\begin{array}{l}\text { poor } \\
\text { feeding }\end{array}$ & heart failure & $\begin{array}{l}\text { poor } \\
\text { feeding }\end{array}$ & $\begin{array}{l}\text { motor } \\
\text { delay }\end{array}$ & n.a. & n.a. \\
\hline dilated CMP & + & + & - & - & $12 / 12$ & $27 / 31$ \\
\hline hypertrophic CMP & - & - & + & - & $0 / 12$ & $1 / 31$ \\
\hline $\begin{array}{l}\text { age at diagnosis of } \\
\text { CMP (months) }\end{array}$ & 4 & 4 & 3 & - & n.a. & $5.5 \pm 7.4$ \\
\hline ventricular arrhythmia & $+c$ & - & - & - & n.a. & $7 / 31^{d}$ \\
\hline heart transplantation & - & - & - & - & $2 / 12^{\mathrm{e}}$ & $0 / 31$ \\
\hline muscle hypotonia & + & + & + & + & $5 / 12$ & n.a. \\
\hline $\begin{array}{l}\text { delayed motor } \\
\text { milestones }\end{array}$ & + & + & + & + & n.a. & $\begin{array}{c}\text { many } \\
\text { patients* }\end{array}$ \\
\hline $\begin{array}{l}\text { growth retardation } \\
\left(<5^{\text {th }} \text { centile }\right)\end{array}$ & + & + & + & - & $8 / 12$ & $15 / 26^{f}$ \\
\hline \multicolumn{7}{|l|}{ Laboratory data } \\
\hline $\begin{array}{l}\text { neutropenia } \\
(<1,000 \mathrm{ANC})\end{array}$ & - & - & + & + & $8 / 12$ & $3 / 12$ \\
\hline $\begin{array}{l}\text { myopathy } \\
(\mathrm{CK}>3.1 \mu \mathrm{kat} / \mathrm{l})\end{array}$ & - & - & - & - & $5 / 12$ & $3 / 20$ \\
\hline $\begin{array}{l}\text { hepatopathy (ALT; } \\
\text { AST > } 0.6 \mu \mathrm{kat} / \mathrm{l})\end{array}$ & + & +8 & - & $+g$ & n.a. & n.a. \\
\hline $\begin{array}{l}\text { 3-MGAuria } \\
\text { (>15 mg/g creatinine) }\end{array}$ & + & + & + & + & $7 / 12$ & n.a. \\
\hline $\begin{array}{l}\text { Age at time } \\
\text { of publication }\end{array}$ & $\begin{array}{l}\text { died aged } \\
2 \text { years }\end{array}$ & 3 years & 13 years & 10 years & $\begin{array}{c}5 \text { living/7 } \\
\text { died }(1997)^{\mathrm{h}}\end{array}$ & $\begin{array}{l}31 \text { living } \\
(2006)^{i}\end{array}$ \\
\hline
\end{tabular}

a - specific mutations or their basic characteristics are available in the references (D'Adamo et al., 1997;

Spencer et al., 2006); n.a. - data not available; b - borderline prematurity (delivered at 37 weeks of gestation); 
IUGR - intrauterine growth retardation; CMP - cardiomyopathy; c - sustained ventricular tachycardia leading to sudden cardiac arrest; $d$ - of 16 patients who were evaluated at $\geq 11$ years of age, 7 (43\%) had documented ventricular arrhythmia; e - heart transplant at the age of 4 and 14 months, respective; $*$ - not further specified; $\mathrm{f}$ - only patients under 18 years of age; ANC - absolute neutrophil count; CK - creatine kinase (>180 U/I); ALT - alanine transaminase (alanine aminotransferase); AST - aspartate transaminase (aspartate aminotransferase); $\mathrm{g}$ - AST elevation only; 3-MGA - 3-methylglutaconic aciduria; $\mathrm{h}$ - mean age at death was $13 \pm 7$ months, mean age of living patients was $11 \pm 5.7$ years; $i-$ age range $1.2-22.6$ years

species. The mutation was not present in Human Tafazzin (TAZ) Gene Mutation and Variation Database (revision Feb 28, 2013; http://www.barthsyndrome.org). Mother of the patient is heterozygous for $c .86 \mathrm{G}>\mathrm{A}$.

In patient 2, a hemizygous mutation c.109+6T $>C$ was found which significantly alters splicing of exon 1 and exon 2. A cDNA analysis revealed the presence of four different altered splicing variants of exon 1 and exon 2 in patient's lymphocytes. In these 4 variants, missing parts of the corresponding exons together with additions of intron 1 sequence into mRNA were found by sequencing. The mutation was not present in Human Tafazzin (TAZ) Gene Mutation and Variation Database (revision Feb 28, 2013; http://www.barthsyndrome.org). Mother of the patient and his maternal grand-mother are heterozygous for c.109+6T $>C$.

In patient 3, TAZ gene sequencing revealed mutation c.280C $>T$ resulting in p.Arg94Cys substitution. The mutation has been described previously (Johnston et al., 1997). Mother of the patient is heterozygous for c.280C $>T$, his sister was negative.

In patient 4, a hemizygous substitution c.584G $>\mathrm{T}$ was found. His mother and sister are heterozygous, the mutation was not found in maternal grand-mother. The mutation changes highly conserved Gly ${ }^{195}$ into Val (p.Gly195Val). Since the mutation c.584G $>\mathrm{T}$ affects the first base of exon 8, altered splicing of TAZ mRNA was suggested. However, TAZ cDNA analysis did not confirm changes in splicing and only mutation c.584G $>T$ was found by sequencing in patient's CDNA. The mutation was not present in Human Tafazzin (TAZ) Gene Mutation and Variation Database (revision Feb 28, 2013; http://www.barthsyndrome.org).

\section{Discussion}

In this paper, we report on the first four diagnosed patients with BTHS in the Czech Republic. It is noteworthy that we have found three novel mutations in the TAZ gene. All of our patients manifested a wide range of clinical features typically associated with BTHS such as cardiomyopathy, delayed motor development, neutropenia and growth retardation originally described by Barth et al. (1983). Survival of patients with BTHS is mainly limited by the severity of cardiac involvement and the severity of neutropenia which can cause sepsis in infancy (Kelley et al., 1991; D'Adamo et al., 1997; Steward et al., 2010). One of our patients died due to malignant arrhythmia at the age of two years; the oldest surviving patient is at present 13 years old. In the work by D'Adamo et al. (1997) 7 out of 12 patients died due to heart failure or cardiac arrest in the mean age $13 \pm 7$ months, 
the average age of the living five patients was $11 \pm 5.7$ years at the time of publication. On the other hand, in the largest case report series published so far (Spencer et al., 2006) all 31 patients, who were seen in the centre twice in 2002 and 2004, survived with the age range 1-22 years. The oldest diagnosed and living patient with BTHS published in the literature was 51 years old (Ronvelia et al., 2012).

\section{Cardiac manifestation}

Cardiomyopathy presenting with poor feeding, failure to thrive and heart failure is the most common leading symptom of BTHS described in the literature (Kelley et al., 1991; Bleyl et al., 1997; D’Adamo et al., 1997; Spencer et al., 2006; Steward et al., 2010), which can be diagnosed even prenatally (Cardonick et al., 1997). In 3 out of 4 our patients the disease presented with poor feeding, failure to thrive or heart failure in the mean age $5.5 \pm 3.8$ months. Only in one of our patients the cardiomyopathy was not documented. This is in agreement with the finding of Spencer et al. (2006) showing that $10 \%$ of patients with BTHS did not develop CMP.

Even though the BTHS might be associated with various type of CMP, the most common type is the dilated one (D'Adamo et al., 1997; Barth et al., 2004; Spencer et al., 2005, 2006). All 12 patients from the cohort of D'Adamo et al. (1997) and $90 \%$ of patients reported by Spencer et al. (2006) had dilated CMP. Only one patient had a hypertrophic CMP (Spencer et al., 2006). Dilated or hypertrophic CMP was documented in two and in a single case of our patient group, respectively. Other clinical features of BTHS have included LV dilatation, LVNC with varying degrees of congestive heart failure and endocardial fibroelastosis (Neustein et al., 1979; Barth et al., 1983; Kelley et al., 1991; D'Adamo et al., 1997; Takeda et al., 2011a). The endocardial fibroelastosis of the left ventricle with an extreme dilatation of both ventricles was found at autopsy in our deceased patient.

Progression of cardiac impairment is variable, not only within families with different genotype, but also within the same family carrying the same mutation (Gedeon et al., 1995; Bleyl et al., 1997; Chen et al., 2002). Data from the literature suggest that in many patients with BTHS, cardiomyopathy is often responsive to standard heart failure medical therapy and may remain stable for many years or may even improve over time (as seen in our patient 2 and 3) (e.g. Spencer et al., 2006). However, individuals with BTHS and severe CMP that leads to death or requires heart transplantation have been observed frequently (Adwani et al., 1995; Bleyl et al., 1997; Steward et al., 2010; Hanke et al., 2012). Heart transplantation was suggested in two of our patients. A remarkable improvement of cardiac function in patient 2 enabled us to remove the patient from the waiting list. Sudden cardiac death prevented patient 1 from undergoing heart transplantation. In the work of D'Adamo et al. (1997) two out of 5 surviving patients underwent heart transplantation (aged 4 and 14 months, respectively).

Other serious and possibly lethal complication in later childhood or adolescence is a relative high incidence of ventricular arrhythmias which can lead to sudden 
cardiac arrest or sustained ventricular tachycardia. Arrhythmias are not in any correlation with the severity of CMP and they may occur in all patients regardless the previous severity of cardiac impairment (Bleyl et al., 1997; Spencer et al., 2005, 2006). Ventricular arrhythmia was documented in 7 out of 16 (43\%) patients who were evaluated at $>11$ years of age by Spencer et al. (2005). In addition, there were 5 cases of cardiac arrest and/or placement of an internal cardiac defibrillator reported (Spencer et al., 2005). One of our patients suffered from sudden cardiac death and in one patient prolonged QTc was demonstrated at the age of 13 years. In the remaining two patients there was no arrhythmia documented until now.

\section{Skeletal myopathy}

Myopathy is a frequent feature of BTHS (Barth et al., 1983; Spencer et al., 2006). Patients have frequently gross motor delay (Christodoulou et al., 1994; Barth et al., 1999) and Gower's sign may be present (Barth et al., 1999). Even though CMP is the most common presenting feature of BTHS, skeletal myopathy and muscle hypotonia may be noted as first. In the work of Spencer et al. (2006) many patients from the set of 31 included into the study had delayed motor developmental milestones (not further specified), but in only $15 \%$ of patients an elevated activity of creatine kinase was documented. There is some evidence from the literature (e.g. Spencer et al., 2006) that skeletal myopathy generally does not limit ambulation, strength improves with age, but excessive fatigue is an important factor in the symptoms related to persisting skeletal myopathy. Muscle hypotonia was noted in all our patients of BTHS shortly after birth and delayed motor milestones were than observed. Patient 3 and 4 experienced fatigue, but are not limited in daily life. Elevated activity of creatine kinase in our patients was not found.

\section{Growth retardation}

Growth failure appears in most patients with BTHS (Barth et al., 1983; Kelley et al., 1991). Results from the work of Spencer et al. (2006) indicate that more than a half of the patients under study appeared below the $5^{\text {th }}$ centile for height and/or weight. In addition, slightly fewer than a half of the group had BMI less than the $5^{\text {th }}$ centile, indicating a relatively poor weight gain in these individuals. Growth failure was noted in 3 out of 4 our patients. It seems reasonable to claim that some patients may have delayed growth spurts and will reach their final height at a later age (Spencer et al., 2006). There is no evidence of deficiency in growth hormone secretion (Barth et al., 2004) although we found decreased levels of IGF-I in the patient 2 and 4. Moreover, there are no confirming data regarding a positive response to growth hormone therapy in the available literature. The authors prefer the opinion that it is better to wait until the patient reaches his final height, which is usually within the normal range (Spencer et al., 2006). All our patients had a relatively low birth weight for gestational age; patient 1 was diagnosed with IUGR. 
In BTHS this is detected frequently and patients are hypotrofic or with low birth weight even though they are born at term (Christodoulou et al., 1994; Steward et al., 2010).

\section{Laboratory findings}

Neutropenia with frequent infections may be another presenting symptom in patients with BTHS and is common (McCanta et al., 2008). Like CMP the spectrum and severity of neutropenia varies between patients but also in the same patient over time. The absolute neutrophil count (ANC) can be decreased mildly but agranulocytosis may be found too, with history of severe infections and sepsis which can be a fatal complication of BTHS (Barth et al., 1983; Kelley et al., 1991; Christodoulou et al., 1994). Neutropenia is either with consistently low levels of circulating neutrophils or may be cyclic with undulating neutrophil levels. A stop in the maturation of neutrophils at the promyelocyte stage is shown in the bone marrow smears from patients with BTHS. The origin of neutropenia was first attributed to escalated apoptosis of neutrophils or their precursors in the bone marrow. The latest research shows that impaired mitochondria in these patients activate reactive oxygen species in the neutrophils and lead to a higher level of phagocytosis by macrophages (Finsterer and Frank, 2013). The treatment of neutropenia includes regular application of G-CSF (Barth et al., 2004; McCanta et al., 2008; Takeda et al., 2011b). These findings are consistent with ours. Neutropenia was not present in two of our patients. On the other hand, patient 4 repeatedly suffered from attacks of aphthous stomatitis and fever as one of the first symptoms of the disease and patient 3 was diagnosed with neutropenia from an early age. Both patients are without increased frequency of infections on G-CSF therapy. Intermittently increased excretion of 3-MGA was noted in urine of all our patients. Increased urinary 3-MGA excretion is a relatively common finding in metabolic disorders, especially in mitochondrial disorders. However, there is a group of disorders with significantly and consistently increased 3-MGA excretion, where 3-MGAuria is a hallmark of the phenotype and the key to diagnosis. At present disorders accompanied by 3-MGAuria are labelled by roman numbers (I-V) and BTHS is classified as a number II. Primary 3-MGAuria (also known as type I) is caused by defective leucine catabolism. As well as all other features of BTHS, 3-MGA might be present only intermittently (Bleyl et al., 1997; Schmidt et al., 2004). Both fasting and increased intake of leucine in diet did not change urinary excretion of 3-MGA in patients with BTHS (Kelley et al., 1991; Christodoulou et al., 1994; Barth et al., 2004; Hauff and Hatch, 2006). So, the exact cause of 3-MGAuria remains to be elucidated.

Hypocholesterolemia is a frequent laboratory finding among patients with BTHS (Kelley et al., 1991; Christodoulou et al., 1994; Barth et al., 2004). However, the blood samples taken from 3 of 4 our patients showed hypocholesterolemia only once in patient 3. It was suggested, that increased levels of 3-MGA in urine is 
due to defect in isoprenoid metabolism, but by cholesterol-rich diet, the levels of 3-MGA were not significantly reduced (Kelley et al., 1991) so the origin of hypocholesterolemia is not well understood, yet. From the other laboratory findings, sometimes mild lactic acidosis or hypoglycemia may occur (Kelley et al., 1991) as a sign of impaired energy production.

Severe lactic acidosis and hypoglycemia is a finding more likely in patients during heart failure or severe bacterial infections (Christodoulou et al., 1994; Yen et al., 2008), which is consistent with our finding in patient 1 , who had normal serum and urine lactate level prior to development of malignant arrhythmia, but these levels have raised several times thereafter also due to poor peripheral perfusion.

Another laboratory marker which may help to establish the diagnosis are attacks of hyperammonemia during metabolic disturbances (Donati et al., 2006; Yen et al., 2008). Hyperammonemia was not documented in our patients.

\section{Molecular-genetic studies}

Up to date more than 100 mutations including deletion of entire TAZ gene or some of its exons has been identified (Human Tafazzin (TAZ) Gene Mutation and Variation Database; HGMD Professional 2012.4) and no correlation between genotype and phenotype has been proved (Johnston et al., 1997; Chen et al., 2002; Vesel et al., 2003). However, impact of 18/21 conserved pathogenic missense mutations on tafazzin function was characterized in Saccharomyces cerevisiae (Claypool et al., 2011; Whited et al., 2012) and seven functional classes of TAZ gene mutation were established (Whited et al., 2012). Mutation c.109+6T $>C$ found in patient 2 belongs to class 1 which includes frameshift and splice-site mutation. Mutation p.Arg94Cys (patient 4) has been studied by Whited et al. (2012) and leads to catalytically inactive protein (class 4 mutations). The remaining 2 novel mutations found in our patients needs to be classified. Nevertheless, we speculate that mutation p.Gly195Val may affect catalytic function of tafazzin since it is localized in putative acyltransferase motif (Claypool et al., 2011).

Although BTHS is an X-linked disease there is a single documented case in female patient presenting with severe heart failures, muscle hypotonia and neutropenia, resulting into sepsis, which ended up fatally in 3 years of age. Molecular analysis found mosaicism for monosomy and for ring X-chromosome with deletion of the long arm of $\mathrm{X}$-chromosome, which included the locus for BTHS (Cosson et al., 2012).

\section{Conclusion}

In the present paper, we report on the clinical, biochemical and molecular characteristics of four patients with Barth syndrome. The most prominent findings in our patients were dilated/hypertrophic CMP, risk of sudden cardiac arrest, muscle hypotonia, growth failure and neutropenia. Intermittently increased excretion of 3-MGA was a consistent laboratory abnormality. In particular, 
the co-occurrence of dilated CMP and 3-MGAuria is highly suggestive of BTHS. In addition, three novel mutations in the TAZ gene were found.

\section{References}

Adwani, S. S., Whitehead, B. F., Rees, P. G., Whitmore, P., Fabre, J. W., Elliott, M. J., de Leval, M. R. (1995) Heart transplantation for dilated cardiomyopathy. Arch. Dis. Child. 73, 447-452.

Barth, P. G., Scholte, H. R., Berden, J. A., Van der Klei-Van Moorsel, J. M., Luyt-Houwen, I. E., Van't Veer-Korthof, E. T., Van der Harten, J. J., Sobotka-Plojhar, M. A. (1983) An X-linked mitochondrial disease affecting cardiac muscle, skeletal muscle and neutrophil leucocytes. J. Neurol. Sci. 62, 327-355.

Barth, P. G., Wanders, R. J. A., Vreken, P., Janssen, E. A. M., Lam, J., Baas, F. (1999) X-linked cardioskeletal myopathy and neutropenia (Barth syndrome). J. Inherit. Metab. Dis. 22, 555-567.

Barth, P. G., Valianpour, F., Bowen, V. M., Lam, J., Duran, M., Vaz, F. M., Wanders, R. J. (2004) X-linked cardioskeletal myopathy and neutropenia (Barth syndrome): an update. Am. J. Med. Genet. A 126A, 349-354.

Bione, S., D’Adamo, P., Maestrini, E., Gedeon, A. K., Bolhuis, P. A., Toniolo, D. (1996) A novel X-linked gene, G4.5. is responsible for Barth syndrome. Nat. Genet. 12, 385-389.

Bleyl, S. B., Mumford, B. R., Thompson, V., Carey, J. C., Pysher, T. J., Chin, T. K., Ward, K. (1997) Neonatal, lethal noncompaction of the left ventricular myocardium is allelic with Barth syndrome. Am. J. Hum. Genet. 61 , 868-872.

Bolhuis, P. A., Hensels, G. W., Hulsebos, T. J. M., Baas, F., Barth, P. G. (1991) Mapping of the locus for X-linked cardioskeletal myopathy with neutropenia and abnormal mitochondria (Barth syndrome) to Xq28. Am.J. Hum. Genet. 48, 481-485.

Brady, A. N., Shehata, B. M., Fernhoff, P. M. (2006) X-linked fetal cardiomyopathy caused by a novel mutation in the TAZ gene. Prenat. Diagn. 26, 462-465.

Brandner, K., Mick, D. U., Frazier, A. E., Taylor, R. D., Meisinger, C., Rehling, P. (2005) Taz1, an outer mitochondrial membrane protein, affects stability and assembly of inner membrane protein complexes: implications for Barth syndrome. Mol. Biol. Cell 16(11), 5202-5214.

Cardonick, E. H., Kuhlman, K., Ganz, E., Pagotto, L. T. (1997) Prenatal clinical expression of 3-methylglutaconic aciduria: Barth syndrome. Prenat. Diagn. 17, 983-988.

Chen, R., Tsuji, T., Ichida, F., Bowles, K. R., Yu, X., Watanabe, S., Hirono, K., Tsubata, S., Hamamichi, Y., Ohta, J., Imai, Y., Bowles, N. E., Miyawaki, T., Towbin, J. A. (2002) Mutation analysis of the G4.5 gene in patients with isolated left ventricular noncompaction. Mol. Genet. Metab. 77, 319-325.

Christodoulou, J., Mclnnes, R. R., Jay, V., Wilson, G., Becker, L. E., Lehotay, D. C., Platt, B. A., Bridg, P. J., Robinson, B. H., Clarke, J. T. R. (1994) Barth syndrome: clinical observations and genetic linkage studies. Am. J. Med. Genet. 50, 255-264.

Claypool, S. M., Whited, K., Srijumnong, S., Han, X., Koehler, C. M. (2011) Barth syndrome mutations that cause tafazzin complex lability. J. Cell Biol. 192(3), 447-462

Cosson, L., Toutain, A., Simard, G., Kulik, W., Matyas, G., Guichet, A., Blasco, H., Maakaroun-Vermesse, Z., Vaillant, M. C., Le Caignec, C., Chantepie, A., Labarthe, F. (2012) Barth syndrome in a female patient. Mol. Genet. Metab. 106, 115-120.

D’Adamo, P., Fassone, L., Gedeon, A., Janssen, E. A. M., Bione, S., Bolhuis, P. A., Barth, P. G., Wilson, M., Haan, E., Orstavik, K. H., Patton, M. A., Green, A. J., Zammarchi, E., Donati, M. A., Toniolo, D. (1997) The X-linked gene G4.5 is responsible for different infantile dilated cardiomyopathies. Am. J. Hum. Genet. 61, 862-867.

Donati, M. A., Malvagia, S., Pasquini, E., Morrone, A., La Marca, G., Garavaglia, B., Toniolo, D., Zammarchi, E. (2006) Barth syndrome presenting with acute metabolic decompensation in the neonatal period. J. Inherit. Metab. Dis. 29(5), 684.

Finsterer, J., Frank, M. (2013) Haematological features in Barth syndrome. Curr. Opin. Hematol. 20(1), 36-40. 
Gedeon, A. K., Wilson, M. J., Colley, A. C., Sillence, D. O., Mulley, J. C. (1995) X linked fatal cardiomyopathy maps to Xq28 and is possibly allelic to Barth syndrome. J. Med. Genet. 32, 383-388.

Hanke, S. P., Gardner, A. B., Lombardi, J. P., Manning, P. B., Nelson, D. P., Towbin, J. A., Jefferies, J. L., Lorts, A. (2012) Left ventricular noncompaction cardiomyopathy in Barth syndrome: an example of an undulating cardiac phenotype necessitating mechanical circulatory support as a bridge to transplantation. Pediatr. Cardiol. 33, 1430-1434.

Hauff, K. D., Hatch, G. M. (2006) Cardiolipin metabolism and Barth syndrome. Prog. Lipid Res. 45, 91-101. Johnston, J., Kelley, R. I., Feigenbaum, A., Cox, G. F., lyer, G. S., Funanage, V. L., Proujansky, R. (1997) Mutation characterization and genotype-phenotype correlation in Barth syndrome. Am. J. Hum. Genet. 61, 1053-1058.

Kelley, R. I., Cheatham, J. P., Clark, B. J., Nigro, M. A., Powell, B. R., Sherwood, G. W., Sladky, J. T. (1991) X-linked dilated cardiomyopathy with neutropenia, growth retardation, and 3-methylglutaconic aciduria. J. Pediatr. 119, 738-747.

Mazzocco, M. M., Henry, A. E., Kelly, R. I. (2007) Barth syndrome is associated with a cognitive phenotype.J. Dev. Behav. Pediatr. 28(1), 22-30.

McCanta, A. C., Chang, A. C., Weiner, K. (2008) Cardiomyopathy in a child with neutropenia and motor delay. Curr. Opin. Pediatr. 20, 605-607.

Neustein, H. B., Lurie, P. R., Dahms, B., Takahashi, M. (1979) An X-linke recessive cardiomyopathy with abnormal mitochondria. Pediatrics 64, 24-29.

Neuwald, A. F. (1997) Barth syndrome may be due to an acyltransferase deficiency. Curr. Biol. 7, 465-466.

Ronvelia, D., Greenwood, J., Platt, J., Hakim, S., Zaragoza, M. V. (2012) Intrafamilial variability for novel TAZ gene mutation: Barth syndrome with dilated cardiomyopathy and heart failure in an infant and left ventricular noncompaction in his great-uncle. Mol. Genet. Metab. 107(3), 428-432.

Schmidt, M. R., Birkebaek, N., Gonzalez, I., Sunde, L. (2004) Barth syndrome without 3-methylglutaconic aciduria. Acta Paediatr. 93, 419-421.

Spencer, C. T., Byrne, B. J., Gewitz, M. H., Wechsler, S. B., Kao, A. C., Gerstenfeld, E. P., Merliss, A. D., Carboni, M. P., Bryant, R. M. (2005) Ventricular arrhythmia in the X-linked cardiomyopathy Barth syndrome. Pediatr. Cardiol. 26, 632-637.

Spencer, C. T., Bryant, R. M., Day, J., Gonzalez, I. L., Colan, S. D., Thompson, W. R., Berthy, J., Redfearn, S. P., Byrne, B. J. (2006) Cardiac and clinical phenotype in Barth syndrome. Pediatrics 118, e337-e346.

Steward, C. G., Newbury-Ecob, R. A., Hastings, R., Smithson, S. F., Tsai-Goodman, B., Quarrell, O. W., Kulik, W., Wanders, R., Pennock, M., Williams, M., Cresswell, J. L., Gonzalez, I. L., Brennan, P. (2010) Barth syndrome: an X-linked cause of fetal cardiomyopathy and stillbirth. Prenat. Diagn. 30(10), 970-976.

Takeda, A., Sudo, A., Yamada, M., Yamazawa, H., Izumi, G., Nishino, I., Ariga, T. (2011a) Barth syndrome diagnosed in the subclinical stage of hearth failure based on a presence of lipid storage myopathy and isolated noncompaction of the ventricular myocardium. Eur. J. Pediatr. 170, 1481-1484.

Takeda, A., Sudo, A., Yamada, M., Yamazawa, H., Izumi, G., Nishino, I., Ariga, T. (2011b) Eponym: Barth syndrome. Eur. J. Pediatr. 170, 1365-1367.

Vesel, S., Stopar-Obreza, M., Trebusak-Podkrajsek, K., Jazbec, J., Podnar, T., Battelino, T. (2003) A novel mutation in the G4.5 (TAZ) gene in a kindred with Barth syndrome. Eur. J. Hum. Genet. 11(1), 97-101.

Vreken, P., Valianpour, F., Nijtmans, L. G., Grivell, L. A., Plecko, B., Wanders, R. J. A., Barth, P. G. (2000) Defective remodeling of cardiolipin and phosphatidylglycerol in Barth syndrome. Biochem. Biophys. Res. Commun. 279, 378-382.

Whited, K., Baile, M. G., Currier, P., Claypool, S. M. (2012) Seven functional classes of Barth syndrome mutation. Hum. Mol. Genet. 22(3), 483-492.

Yen, T., Hwu, W., Chien, Y. (2008) Acute metabolic decompensation and sudden death in Barth syndrome: report of a family and a literature review. Eur. J. Pediatr. 167, 941-944.

Novel Mutations in the TAZ Gene in Patients with Barth Syndrome 